\title{
Association of Peripheral Insulin Resistance and Other Markers of Type 2 Diabetes Mellitus with Brain Amyloid Deposition in Healthy Individuals at Risk of Dementia
}

Timo Pekkala ${ }^{\mathrm{a}}$, Anette Hall ${ }^{\mathrm{a}, *}$, Francesca Mangialasche ${ }^{\mathrm{b}, \mathrm{c}}$, Nina Kemppainen ${ }^{\mathrm{d}, \mathrm{e}}$, Patrizia Mecocci $^{\mathrm{f}}$, Tiia Ngandu ${ }^{\text {b,g }}$, Juha O. Rinne ${ }^{\mathrm{d}, \mathrm{e}}$, Hilkka Soininen ${ }^{\mathrm{a}, \mathrm{h}}$, Jaakko Tuomilehto ${ }^{\mathrm{g}, \mathrm{i}, \mathrm{j}}$, Miia Kivipelto $^{\mathrm{a}, \mathrm{b}, \mathrm{k}, 1}$ and Alina Solomon ${ }^{\mathrm{a}, \mathrm{b}}$

${ }^{a}$ Institute of Clinical Medicine/Neurology, University of Eastern Finland, Kuopio, Finland

${ }^{\mathrm{b}}$ Division of Clinical Geriatrics, Center for Alzheimer Research, NVS, Karolinska Institutet, Stockholm, Sweden ${ }^{\mathrm{c}}$ Aging Research Center, NVS, Karolinska Institutet and Stockholm University, Stockholm, Sweden

${ }^{\mathrm{d}}$ Turku PET Centre, University of Turku, Turku, Finland

${ }^{\mathrm{e}}$ Division of Clinical Neurosciences, Turku University Hospital, Turku, Finland

${ }^{\mathrm{f}}$ Department of Medicine, Institute of Gerontology and Geriatrics, University of Perugia, Perugia, Italy

${ }^{\mathrm{g}}$ Public Health Promotion Unit, Finnish Institute for Health and Welfare, Helsinki, Finland

${ }^{\mathrm{h}}$ Neurocenter, Neurology, Kuopio University Hospital, Kuopio, Finland

${ }^{\mathrm{i}}$ Department of Public Health, University of Helsinki, Helsinki, Finland



${ }^{\mathrm{k}}$ Institute of Public Health and Clinical Nutrition, University of Eastern Finland, Kuopio, Finland

${ }^{1}$ Ageing Epidemiology Research Unit, School of Public Health, Imperial College London, London,

United Kingdom

Handling Associate Editor: J. Wesson Ashford

Accepted 22 May 2020

\begin{abstract}
We explored the association of type 2 diabetes related blood markers with brain amyloid accumulation on PiB-PET scans in 41 participants from the FINGER PET sub-study. We built logistic regression models for brain amyloid status with 12 plasma markers of glucose and lipid metabolism, controlled for diabetes and APOE $\varepsilon 4$ carrier status. Lower levels of insulin, insulin resistance index (HOMA-IR), C-peptide, and plasminogen activator (PAI-1) were associated with amyloid positive status, although the results were not significant after adjusting for multiple testing. None of the models found evidence for associations between amyloid status and fasting glucose or HbA1c.
\end{abstract}

Keywords: Amyloid- $\beta$, apolipoprotein E, plasminogen activator, positron emission tomography, type 2 diabetes

\footnotetext{
${ }^{*}$ Correspondence to: Anette Hall, Neurology, Institute of Clinical Medicine, University of Eastern Finland, P.O. Box 1627,
}

70211 Kuopio, Finland. Tel.: +358 $50 \quad 5392167$; E-mail: anette.hall@uef.fi. 


\section{INTRODUCTION}

The association of type 2 diabetes (DM2) and insulin resistance (IR) with formation of amyloid- $\beta$ plaques in Alzheimer's disease (AD) is still unclear. $\mathrm{DM} 2$ is a risk factor for cognitive impairment and for the clinical diagnosis of probable AD dementia [1]. However, autopsy studies have consistently found that DM2 diagnosis is associated with small vessel pathology and not with AD pathological hallmarks (amyloid- $\beta$ plaques and neurofibrillary tangles) $[2$, 3]. IR, an indicator of a pre-diabetic state and a hallmark of DM2, has been associated with amyloid accumulation in middle-aged [4] and late-middleaged [5], but not in older [6] cognitively healthy individuals. A study of older individuals reported no relation of lifelong IR exposure with either in vivo or postmortem measures of brain amyloid pathology [7]. The mechanisms linking amyloid- $\beta$ accumulation and insulin resistance are unclear, and hypotheses include, e.g., dysregulated hormonal signaling and "type 3 diabetes" of the brain [8]. We explored the association of peripheral blood markers of IR and DM2 with amyloid- $\beta$ accumulation on PET scans in older individuals at risk for dementia, but without dementia or substantial cognitive decline. Our hypothesis was that we would find associations between exploratory diabetes blood markers and an amyloid positive status in PET.

\section{METHODS}

The study population included 41 participants in the Finnish Geriatric Intervention Study to Prevent Cognitive Impairment and Disability (FINGER) exploratory PET sub-study who had available data on IR and DM2-related blood markers (fasting blood glucose, insulin, HbA1c, and a 12-itemBio-Plex Pro Human Diabetes assay). The FINGER main study [9] and PET sub-study [10] have previously been described in detail. Briefly, FINGER investigated the cognitive benefits of a 2-year multi domain lifestyle intervention versus regular health advice in 1,260 individuals aged 60-77 years from the general population. Inclusion criteria were elevated dementia risk based on Cardiovascular Risk Factors, Aging and Dementia (CAIDE) score [11], and cognitive performance at mean level or slightly lower than expected for age according to Finnish population norms for the Consortium to Establish a Registry for Alzheimer's Disease (CERAD) test. ${ }^{11} \mathrm{C}$-Pittsburgh compound
B (PiB) PET scans were conducted at the Turku PET Centre. MR-based attenuation corrected images with summated PET data over 60-90 min were visually assessed as amyloid- $\beta$ positive or negative by two-party consensus agreement. Positive individuals showed cortical accumulation in at least one ADtypical region, and negative individuals showed only nonspecific retention in white matter [10]. The FINGER study was approved by the Coordinating Ethics Committee of the Hospital District of Helsinki and Uusimaa. All participants gave written informed consent at the screening and baseline visits, and for the exploratory neuroimaging sub-study.

In the FINGER study, venous blood samples were taken at baseline in fasting status and using EDTA tubes. Plasma aliquots were stored at $-80^{\circ} \mathrm{C}$ until analysis. Twelve markers related to glucose and lipid metabolism were analyzed using the multiplex suspension array system Bio-Plex Luminex® 200 instrument, (Bio-Rad Laboratories, Hercules, CA, USA), with the Bio-Plex Pro Human Diabetes 10-plex panel (C-peptide; ghrelin; GIP, gastric inhibitory polypeptide; GLP-1, glucagon-like peptide-1; glucagon; insulin; leptin; PAI-1; resistin; visfatin) and 2-plex panel (adiponectin, adipsin) (BioRad Laboratories, Hercules, CA, USA). The assays were performed in one batch, and samples preparation and setting of the system running protocol were done following the manufacturer's instructions (www.Biorad.com).

In brief, plasma samples $(10 \mu \mathrm{l})$ were first diluted ( $1: 400$ for adipsin adiponectin; $1: 4$ for all the other compounds) using Serum Based Diluent provided by the manufacturer. Assay beads $(50 \mu \mathrm{l})$ were transferred in the 96-well plates and washed twice with wash buffer. Then, standards and plasma samples $(50 \mu \mathrm{l})$ were added to the appropriate wells. Plates were incubated for $1 \mathrm{~h}$ in a dark room, with mild agitation at room temperature. The fluid was then removed by vacuum and wells were washed three times with wash buffer. Detection antibodies $(25 \mu \mathrm{l})$ were added to each well, and plates were incubated for $30 \mathrm{~min}$ in a dark room, with mild agitation at room temperature. The fluorescent conjugate StreptavidinPhycoerythrin $(60 \mu \mathrm{l})$ was then added to each well and plates incubated for $10 \mathrm{~min}$ at room temperature. Finally, plates were washed with wash buffer and assay beads were resuspended in assay buffer (125 $\mu \mathrm{l}$ in each well), and plate reading was done with the Bio-Plex Luminex ${ }^{\circledR} 200$ instrument.

All samples and standards were run in duplicate and were measured as $\mathrm{pg} / \mathrm{ml}$. Quality controls were 
performed according to the manufacturer guidelines to ensure accuracy of measurements. The intra-assay coefficient of variability (CV) for all compounds ranged from 1 to $2 \%$. The detection limits (in $\mathrm{pg} / \mathrm{ml}$ ) were the following: 32.7 for Adiponectin; 17 for Adipsin; 14.5 for C-peptide; 1.2 for ghrelin; 0.8 for GIP; 5.3 for GLP-1; 4.9 for glucagon; 1 for insulin; 3.1 for leptin; 2.2 for PAI-1; 1.3 for resistin; 37.1 for visfatin). All sample results below the lower limit of quantitation were classified as missing data.

After the plate reading, the results files were generated using Bio-Plex Manager software 4 (Bio-Rad Laboratories, Hercules, CA, USA).

Data from the FINGER baseline visit, before the start of the intervention, was used in this study. Diabetes diagnoses were self-reported at the screening visit interview with the study physician. The homeostatic model assessment of insulin resistance index (HOMA-IR) was calculated based on fasting blood insulin and glucose measures. APOE genotype was determined as described previously [12]. We built a logistic regression model for brain amyloid- $\beta$ status based on log-transformed diabetes markers, and diabetes status (yes/no) and $A P O E \varepsilon 4$ carrier status (yes/no) as confounders. Goodness of model fit was assessed by calculating the percentage of deviance of the fit explained. We corrected for multiple comparisons using the false discovery rate (FDR) method [13]. All analyses were performed using MATLAB R2017b (function mnrfit).

\section{RESULTS}

The participants' mean age (SD) was 71.1 (5.0) years, $51 \%$ were female, $15 \%$ had diabetes, $29 \%$ were APOE $\varepsilon 4$ carriers, and $39 \%$ had amyloid positive PiB-PET scans. All participants diagnosed with diabetes were receiving treatment: five were using oral glucose-lowering medication and one was using a combination of oral glucose-lowering medication and insulin. The individual receiving combination therapy was amyloid negative. Amyloid- $\beta$ prevalence was $37 \%$ in non-diabetics and $50 \%$ in diabetics ( $p$ value for difference 0.57 ). APOE4 prevalence was $31 \%$ in non-diabetics and $17 \%$ in diabetics (p-value 0.48 ). One person with diabetes had a history of stroke (amyloid positive), and another person with diabetes had a history of myocardial infarction (amyloid negative).

Table 1 summarizes population characteristics by amyloid- $\beta$ status. APOE $\varepsilon 4$ prevalence was significantly higher in the amyloid positive group (56\% versus $12 \%, p=0.003)$. No statistically significant differences in age, sex, body mass index (BMI), diabetes status, or history of stroke or myocardial infarction were observed. IR and DM2-related markers by amyloid- $\beta$ status are shown in Table 2 . Insulin and plasminogen activator inhibitor-1 (PAI-1) concentrations were significantly lower in amyloid positive compared with negative individuals $(p<0.05)$. C-peptide and HOMA-IRwere also lower in the amyloid positive groups, but differences were significant only at the $90 \%$ confidence level. Other markers showed no significant between-group differences.

In the logistic regression model adjusted for diabetes status and APOE genotype (Table 2), higher levels of insulin, HOMA-IR, C-peptide, and PAI1 were significantly associated with lower odds of amyloid positivity. After FDR correction, these four markers were significant only at the $90 \%$ confidence level. Models with either BMI, age, or sex as additional confounders showed a similar pattern, including after FDR correction. Goodness of fit of the LR model was also highest for models including insulin, HOMA-IR, C-peptide, and PAI-1. Fit was worse in all cases when APOE was removed from the model.

A further exploratory model was built to assess the joint effect of PAI-1 and IR related markers.

Table 1

Baseline population characteristics by amyloid status

\begin{tabular}{lccc}
\hline & $\begin{array}{c}\text { Amyloid } \\
\text { negative }\end{array}$ & $\begin{array}{c}\text { Amyloid } \\
\text { positive }\end{array}$ & $\begin{array}{c}p \\
p\end{array}$ \\
\hline $\mathrm{N}$ & 25 & 16 & \\
Sex $(\%$ female) & $52 \%$ & $50 \%$ & 0.914 \\
APOE $\varepsilon 4$ carrier $(\%)$ & $12 \%$ & $56 \%$ & 0.003 \\
Age & $70.2(5.6)$ & $72.4(3.0)$ & 0.234 \\
BMI & $28.1(3.8)$ & $26.1(2.8)$ & 0.080 \\
Diabetic $(\%)$ & $12 \%$ & $19 \%$ & 0.570 \\
History of stroke $(\%)$ & $12 \%$ & $6 \%$ & 1.000 \\
History of myocardial infarction $(\%)$ & $8 \%$ & $13 \%$ & 0.637 \\
\hline
\end{tabular}


Table 2

Associations of IR and DM2-related markers with amyloid status

\begin{tabular}{|c|c|c|c|c|c|c|c|c|}
\hline \multirow[b]{3}{*}{ Metabolic marker } & \multicolumn{3}{|c|}{ Mean concentration (SD) } & \multicolumn{5}{|c|}{ Logistic regression model } \\
\hline & \multirow{2}{*}{$\begin{array}{l}\text { Amyloid } \\
\text { negative }\end{array}$} & \multirow{2}{*}{$\begin{array}{l}\text { Amyloid } \\
\text { positive }\end{array}$} & \multirow[t]{2}{*}{$p^{\mathrm{a}}$} & \multirow{2}{*}{$\begin{array}{c}\mathrm{B}^{\mathrm{b}} \\
(95 \% \text { confidence interval) }\end{array}$} & \multirow[b]{2}{*}{$p$} & \multirow{2}{*}{$\begin{array}{c}\text { Adjusted } \\
p\end{array}$} & \multicolumn{2}{|c|}{ Goodness of fit ${ }^{\mathrm{c}}$} \\
\hline & & & & & & & with $A P O E$ & without $A P O E$ \\
\hline C-Peptide $\left(10^{3} \mathrm{pg} / \mathrm{ml}\right)$ & $1.31(0.61)$ & $0.95(0.45)$ & 0.056 & $-5.70(-10.35--1.05)$ & 0.016 & 0.072 & $33.4 \%$ & $9.8 \%$ \\
\hline Ghrelin $\left(10^{3} \mathrm{pg} / \mathrm{ml}\right)$ & $1.57(0.51)$ & $1.55(0.39)$ & 0.936 & $0.11(-6.07-6.29)$ & 0.972 & 0.998 & $19.0 \%$ & $0.6 \%$ \\
\hline $\operatorname{GIP}\left(10^{3} \mathrm{pg} / \mathrm{ml}\right)$ & $0.29(0.12)$ & $0.29(0.16)$ & 0.479 & $-1.53(-5.39-2.32)$ & 0.436 & 0.689 & $20.1 \%$ & $1.4 \%$ \\
\hline GLP-1 $\left(10^{3} \mathrm{pg} / \mathrm{ml}\right)$ & $0.59(0.11)$ & $0.58(0.08)$ & 0.224 & $0.01(-8.79-8.81)$ & 0.998 & 0.998 & $19.0 \%$ & $0.7 \%$ \\
\hline Glucagon $\left(10^{3} \mathrm{pg} / \mathrm{ml}\right)$ & $1.07(0.23)$ & $1.00(0.17)$ & 0.530 & $-2.14(-11.30-7.01)$ & 0.646 & 0.808 & $19.4 \%$ & $2.8 \%$ \\
\hline Insulin $\left(10^{3} \mathrm{pg} / \mathrm{ml}\right)$ & $0.27(0.17)$ & $0.17(0.09)$ & 0.036 & $-4.54(-8.26--0.81)$ & 0.017 & 0.072 & $33.2 \%$ & $13.8 \%$ \\
\hline Leptin $\left(10^{3} \mathrm{pg} / \mathrm{ml}\right)$ & $7.55(4.79)$ & $6.06(5.15)$ & 0.145 & $-1.63(-4.07-0.81)$ & 0.191 & 0.569 & $22.2 \%$ & $3.6 \%$ \\
\hline PAI- $1\left(10^{3} \mathrm{pg} / \mathrm{ml}\right)$ & $5.31(1.32)$ & $4.16(0.62)$ & 0.003 & $-13.27(-23.93--2.61)$ & 0.015 & 0.072 & $36.0 \%$ & $20.0 \%$ \\
\hline Resistin $\left(10^{3} \mathrm{pg} / \mathrm{ml}\right)$ & $2.22(0.56)$ & $2.03(0.46)$ & 0.316 & $-3.67(-10.13-2.79)$ & 0.266 & 0.569 & $21.3 \%$ & $2.2 \%$ \\
\hline Visfatin $\left(10^{3} \mathrm{pg} / \mathrm{ml}\right)$ & $4.83(2.25)$ & $4.43(2.30)$ & 0.224 & $-2.03(-6.77-2.71)$ & 0.401 & 0.689 & $20.3 \%$ & $2.8 \%$ \\
\hline Adiponectin $\left(10^{6} \mathrm{pg} / \mathrm{ml}\right)$ & $5.45(3.44)$ & $6.03(3.82)$ & 0.548 & $-0.25(-2.30-1.79)$ & 0.808 & 0.932 & $19.1 \%$ & $1.2 \%$ \\
\hline $\operatorname{Adipsin}\left(10^{6} \mathrm{pg} / \mathrm{ml}\right)$ & $1.21(0.46)$ & $1.45(0.89)$ & 0.925 & $1.08(-2.06-4.22)$ & 0.500 & 0.689 & $20.1 \%$ & $2.1 \%$ \\
\hline fP-Glucose (mmol/l) & $5.92(0.88)$ & $6.30(1.17)$ & 0.303 & $4.80(-9.33-18.93)$ & 0.505 & 0.689 & $19.8 \%$ & $2.4 \%$ \\
\hline B-HbAlc $(\mathrm{mmol} / \mathrm{mol})$ & $36.72(4.11)$ & $37.25(4.63)$ & 0.957 & $14.96(-10.94-40.86)$ & 0.258 & 0.569 & $21.4 \%$ & $0.7 \%$ \\
\hline HOMA-IR $\left(\mathrm{mmol} \cdot \mathrm{mU} / \mathrm{l}^{2}\right)$ & $2.06(1.24)$ & $1.33(0.71)$ & 0.060 & $-4.52(-8.31--0.74)$ & 0.019 & 0.072 & $32.4 \%$ & $11.9 \%$ \\
\hline
\end{tabular}

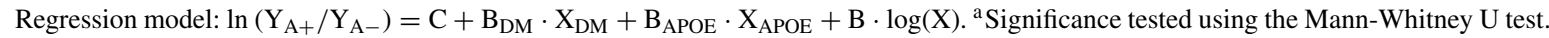
${ }^{\mathrm{b}}$ Coefficient of log-transformed values. ${ }^{\mathrm{c}}$ Goodness of fit expressed in percentage of deviance explained. fP-Glucose, fasting plasma glucose; GIP, gastric inhibitory polypeptide; GLP-1, glucagon-like peptide-1; PAI-1, plasminogen activator inhibitor-1; B-HbA1c, blood glycated hemoglobin.

With DM status, $A P O E$, and PAI-1 as confounders, $p$-values were insignificant for insulin, HOMA-IR, C-peptide, fasting glucose, and HbAlc. The coefficient of PAI-1 was insignificant in models including insulin, HOMA-IR, and C-peptide, and significant for fasting glucose, $\mathrm{HbA} 1 \mathrm{c}$, and all other tested analytes.

\section{DISCUSSION}

Results from the FINGER PET exploratory substudy suggested slightly better insulin homeostasis and related markers in amyloid positive older individuals at risk for dementia, but without dementia or substantial cognitive impairment. Although DM2 has been indicated as a risk factor for dementia and $\mathrm{AD}$ [1], it is not fully clear whether the underlying mechanisms are amyloid-related. Peripheral IR has been linked to IR in the brain, which may affect amyloid- $\beta$ pathology through e.g. neuroinflammatory pathways or competitive cleavage of insulin and amyloid- $\beta$ by the same enzyme [8]. However, previous studies investigating peripheral IR and brain amyloid- $\beta$ in CSFor on PET scans in cognitively healthy individuals have reported no associations at older ages, and mixed findings in middle-aged populations [4-6, 14]. Ekblad et al. [4] found that midlife HOMA-IR, taken 15 years previous to the PET -scan, associated with greater brain amyloid- $\beta$ accumulation in elderly individuals without dementia, in both carriers and noncarriers of $A P O E \varepsilon 4$ genotype, but the same association was not detected at the time of the scan in late-life. No associations have also been reported in people with mild cognitive impairment or $\mathrm{AD}$ [6].

Our results contrast with earlier no-association findings in the elderly, possibly due to the specific risk profile of the FINGER population. Peripheral IR and DM2 may also contribute to cognitive decline via vascular-related mechanisms. Interestingly, an autopsy study in the $85+$ age group showed less amyloid- $\beta$ pathology and more cerebrovascular pathology in people with diabetes, who also had an increased risk of AD dementia [15]. It was suggested that, in people with diabetes and vascular pathology, less amyloid- $\beta$ pathology may be needed to trigger the onset of dementia. FINGER study participants had cognitive performance at the mean level or slightly lower than expected for age, and they were also at risk for dementia based on the CAIDE score including age, sex, education, BMI, systolic blood pressure, total cholesterol, and physical activity [11]. The cognitive performance of a participant could be hypothesized to be determined by a similar interplay of amyloid- $\beta$ - and vascular-related mechanisms, e.g., poorer insulin homeostasis and higher vascularrelated risk in amyloid negative individuals. It is also possible that FINGER participants with lower IR represent a selected group that has maintained better insulin homeostasis despite elevated cardiovascular risk. The mechanisms linking IR and amyloid- $\beta$ accumulation may be different in this specific group. 
To our knowledge, this is the first study investigating the association of peripheral blood PAI-1 level and invivo brain amyloid- $\beta$ markers. Higher PAI-1 level seemed to be protective against amyloid- $\beta$ accumulation, although not significantly after correction for multiple comparisons. The effect was not seen in models including both PAI-1 and IR-related markers. PAI-1 in CSF has in prior studies been reported to have no association with AD status [16, 17]. PAI-1 down regulates the activity of the protein-cleaving plasmin system, and it is considered a risk factor for atherosclerosis due to its prothrombotic effect. In the population-based Framingham Offspring Study, higher fasting insulin level was associated, among other things, with increased PAI-1 levels [18]. In the brain, however, PAI-1 and the plasmin system may interact with amyloid- $\beta$ fibrils and possibly affect plaque formation [19], or be directly neuroprotective [20]. A previous study showed that increases in blood levels of PAI-1 were associated with white matter integrity loss in stroke-free, cognitively normal individuals aged 50-65 years and also reported an association of PAI-1 with lower performance in speed or visuomotor coordination [21]. It is unclear if the association suggested in the present study was mediated through effects in the brain, or if amyloid- $\beta$ load was reduced due to effects in the cardiovascular system.

The main strength of this study is the assessment of a comprehensive assay of IR and DM2-related markers in relation to brain amyloid- $\beta$ accumulation on PiB-PET, which has not been previously done. However, the small sample size is a key limitation, restricting statistical power and the ability to control for other potentially confounding factors. Additionally, overall amyloid- $\beta$ status was determined visually from scans, and no region-specific analyses were conducted. Our exploratory study adds to the growing amount of data on the associations of IR and DM2-related markers with AD-related pathology. Future studies in larger populations and with longitudinal data should further investigate these associations, taking into account, e.g., APOE genotype, degree of vascular pathology, type of DM2 treatment, and level of glycemic control.

\section{ACKNOWLEDGMENTS}

The study was funded by European Research Council grant 804371; Academy of Finland, Finnish Social Insurance Institution, Alzheimer's Research and Prevention Foundation, Alzheimer Association, Yrjö Jahnsson Foundation, Juho Vainio Foundation (Finland); Swedish Research Council, Alzheimerfonden, Region Stockholm ALF and NSV, Center for Innovative Medicine (CIMED) at Karolinska Institutet, Knut and Alice Wallenberg Foundation, Stiftelsen Stockholms sjukhem, Konung Gustaf V:s och Drottning Victorias Frimurarstiftelse (Sweden); Joint Program of Neurodegenerative Disorders - prevention (MIND-AD). J.O. Rinne was funded by the Sigrid Juselius Foundation, Finnish State Research Funding, Academy of Finland (grant 310962).

We thank all participants and members of the FINGER study group for their cooperation in data collection and management.

Authors' disclosures available online (https:// www.j-alz.com/manuscript-disclosures/20-0145r2).

\section{REFERENCES}

[1] Cheng G, Huang C, Deng H, Wang H (2012) Diabetes as a risk factor for dementia and mild cognitive impairment: a meta-analysis of longitudinal studies. Intern Med $\mathbf{J} \mathbf{4 2}$, 484-491.

[2] Abner EL, Nelson PT, Kryscio RJ, Schmitt FA, Fardo DW, Woltjer RL, Cairns NJ, Yu L, Dodge HH, Xiong C, Masaki K, Tyas SL, David A. Bennett DA, Schneider JA, Arvanitakis Z (2016) Diabetes is associated with cerebrovascular but not Alzheimer neuropathology. Alzheimers Dement 12, 882-889.

[3] Pruzin JJ, Nelson PT, Abner EL, Arvanitakis Z (2018) Review: Relationship of type 2 diabetes to human brain pathology. Neuropathol Appl Neurobiol 44, 347-362.

[4] Ekblad LL, Johansson J, Helin S, Viitanen M, Laine H, Puukka P, Jula A, Rinne JO (2018) Midlife insulin resistance, APOE genotype, and late-life brain amyloid accumulation. Neurology 90, e1150-e1157.

[5] Willette AA, Johnson SC, Birdsill AC, Sager MA, Christian B, Baker LD, Craft S, Oh J, Statz E, Hermann BP, Jonaitis EM, Koscik RL, La Rue A, Asthana S, Bendlin BB (2015) Insulin resistance predicts brain amyloid deposition in late middle-aged adults. Alzheimers Dement 11, 504-510.e1.

[6] Laws SM, Gaskin S, Woodfield A, Srikanth V, Bruce D, Fraser PE, Porter T, Newsholme P, Wijesekara N, Burnham S, Doré V, Li QX, Maruff P, Masters CL, Rainey-Smith S, Rowe CC, Salvado O, Villemagne VL, Martins RN, Verdile $\mathrm{G}$ (2017) Insulin resistance is associated with reductions in specific cognitive domains and increases in CSF tau in cognitively normal adults. Sci Rep 7, 9766.

[7] Thambisetty M, Jeffrey Metter E, Yang A, Dolan H, Marano C, Zonderman AB, Troncoso JC, Zhou Y, Wong DF, Ferrucci L, Egan J, Resnick SM, O’Brien RJ (2013) Glucose intolerance, insulin resistance, and pathological features of Alzheimer disease in the Baltimore Longitudinal Study of Aging. JAMA Neurol 70, 1167-1172.

[8] de la Monte SM (2017) Insulin resistance and neurodegeneration: Progress towards the development of new therapeutics for Alzheimer's disease. Drugs 77, 47-65.

[9] Ngandu T, Lehtisalo J, Solomon A, Levälahti E, Ahtiluoto S, Antikainen R, Bäckman L, Hänninen T, Jula A, Laatikainen 
T, Lindström J, Mangialasche F, Paajanen T, Pajala S, Peltonen M, Rauramaa R, Stigsdotter-Neely A, Strandberg T, Tuomilehto J, Soininen H, Kivipelto M (2015) A 2 year multidomain intervention of diet, exercise, cognitive training, and vascular risk monitoring versus control to prevent cognitive decline in at-risk elderly people (FINGER): A randomised controlled trial. Lancet 385, 2255-2263.

[10] Kemppainen N, Johansson J, Teuho J, Parkkola R, Joutsa J, Ngandu T, Solomon A, Stephen R, Liu Y, Hänninen T, Paajanen T, Laatikainen T, Soininen H, Jula A, Rokka J, Rissanen E, Vahlberg T, Peltoniemi J, Kivipelto M, Rinne JO (2018) Brain amyloid load and its associations with cognition and vascular risk factors in FINGER study. Neurology 90, e206-e213.

[11] Kivipelto M, Ngandu T, Laatikainen T, Winblad B, Soininen $\mathrm{H}$, Tuomilehto J (2006) Risk score for the prediction of dementia risk in 20 years among middle aged people: A longitudinal, population-based study. Lancet Neurol 5, 735741.

[12] Stephen R, Liu Y, Ngandu T, Rinne JO, Kemppainen $\mathrm{N}$, Parkkola R, Laatikainen $\mathrm{T}$, Paajanen $\mathrm{T}$, Hänninen T, Strandberg T, Antikainen R, Tuomilehto J, Keinänen Kiukaanniemi S, Vanninen R, Helisalmi S, Levälahti E, Kivipelto M, Soininen H, Solomon A (2017) Associations of CAIDE Dementia Risk Score with MRI, PIB-PET measures, and cognition. J Alzheimers Dis 59, 695-705.

[13] Benjamini, Y, Hochberg, Y (1995) Controlling the false discovery rate: A practical and powerful approach to multiple testing. J R Stat Soc Series B Stat Methodol 57, 289-300.

[14] Westwood S, Liu B, Baird AL, Anand S, Nevado-Holgado AJ, Newby D, Pikkarainen, M, Hallikainen M, Kuusisto J, Streffer JR, Novak G, Blennow K, Andreasson U, Zetterberg H, Smith U, Laakso M, Soininen H, Lovestone S (2017) The influence of insulin resistance on cerebrospinal fluid and plasma biomarkers of Alzheimer's pathology. Alzheimers Res Ther $\mathbf{9}, 31$.

[15] Ahtiluoto S, Polvikoski T, Peltonen M, Solomon A, Tuomilehto J, Winblad B, Sulkava R, Kivipelto M (2010)
Diabetes, Alzheimer disease, and vascular dementia: A population-based neuropathologic study. Neurology 75, 1195-1202.

[16] Martorana A, Sancesario GM, Esposito Z, Nuccetelli M, Sorge R, Formosa A, Dinallo V, Bernardi G, Bernardini S, Sancesario G (2012) Plasmin system of Alzheimer's disease patients: CSF analysis. J Neural Transm (Vienna) 119, 763769.

[17] Leung YY, Toledo JB, Nefedov A, Polikar R, Raghavan N, Xie SX, Farnum M, Schultz T, Baek Y, Deerlin VV, Hu WT, Holtzman DM, Fagan AM, Perrin RJ, Grossman M, Soares HD, Kling MA, Mailman M, Arnold SE, Narayan VA, Lee VM, Shaw LM, Baker D, Wittenberg GM, Trojanowski JQ, Wang LS (2015) Identifying amyloid pathology-related cerebrospinal fluid biomarkers for Alzheimer's disease in a multicohort study. Alzheimers Dement (Amst) 1, 339-348.

[18] Meigs JB, Mittleman MA, Nathan DM, Tofler GH, Singer DE, Murphy-Sheehy PM, Lipinska I, D'Agostino RB, Wilson PW (2000) Hyperinsulinemia, hyperglycemia, and impaired hemostasis: The Framingham Offspring Study. JAMA 283, 221-228.

[19] Bi Oh S, Suh N, Kim I, Lee, J-Y (2015) Impacts of aging and amyloid- $\beta$ deposition on plasminogen activators and plasminogen activator inhibitor- 1 in the $\mathrm{Tg} 2576$ mouse model of Alzheimer's disease. Brain Res 1597, 159-167.

[20] Cho H, Joo Y, Kim S, Woo R-S, Lee SH, Kim H-S (2013) Plasminogen activator inhibitor-1 promotes synaptogenesis and protects against $A \beta 1-42$-induced neurotoxicity in primary cultured hippocampal neurons. Int J Neurosci 123, 42-49.

[21] Miralbell J, Soriano JJ, Spulber G, López-Cancio E, Arenillas JF, Bargalló N, Galán A, Barrios MT, Cáceres C, Alzamora MT, Pera G, Kivipelto M, Wahlund LO, Dávalos A, Mataró M (2012) Structural brain changes and cognition in relation to markers of vascular dysfunction. Neurobiol Aging 33, 1003.e9-17. 